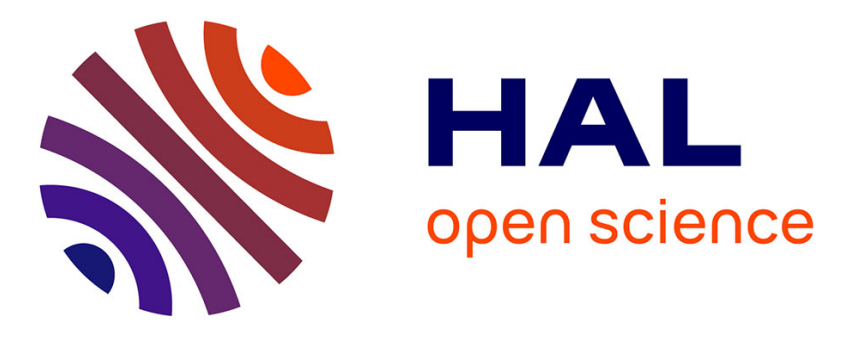

\title{
On the Influence of Oxygen on the Degradation of Fe-N-C Catalysts
}

Kavita Kumar, Laetitia Dubau, Michel Mermoux, Jingkun Li, Andrea Zitolo, Jaysen Nelayah, Frederic Jaouen, Frédéric Maillard

\section{- To cite this version:}

Kavita Kumar, Laetitia Dubau, Michel Mermoux, Jingkun Li, Andrea Zitolo, et al.. On the Influence of Oxygen on the Degradation of Fe-N-C Catalysts. Angewandte Chemie, 2020, 59, pp.3235-3243. 10.1002/ange.201912451 . hal-02464078

\section{HAL Id: hal-02464078 \\ https://hal.science/hal-02464078}

Submitted on 2 Feb 2020

HAL is a multi-disciplinary open access archive for the deposit and dissemination of scientific research documents, whether they are published or not. The documents may come from teaching and research institutions in France or abroad, or from public or private research centers.
L'archive ouverte pluridisciplinaire HAL, est destinée au dépôt et à la diffusion de documents scientifiques de niveau recherche, publiés ou non, émanant des établissements d'enseignement et de recherche français ou étrangers, des laboratoires publics ou privés. 


\title{
On the Influence of Oxygen On the Degradation of Fe-N-C Catalysts
}

\author{
Kavita Kumar, Laetitia Dubau, Michel Mermoux, Jingkun Li, Andrea Zitolo, Jaysen Nelayah, Frédéric \\ Jaouen, ${ }^{*}$ Frédéric Maillard*
}

\begin{abstract}
Precious metal-free catalysts for oxygen reduction reaction (ORR) in proton exchange membrane fuel cells are gaining momentum, with $\mathrm{Fe}-\mathrm{N}-\mathrm{C}$ catalysts comprising atomic $\mathrm{FeN}_{\mathrm{x}}$ sites the most promising candidate. Research and development is shifting from activity targets to improved stability of Fe-N-C catalysts in fuel cells. Their durability has hitherto been extensively studied using accelerated stress tests (AST) performed at room temperature and in inert-gas saturated acidic $\mathrm{pH}$ electrolyte. Here, we reveal stronger degradation of the Fe-N-C structure and four times higher ORR activity loss when performing load cycling AST in $\mathrm{O}_{2}-$ vs. Ar-saturated $\mathrm{pH} 1$ electrolyte. Raman spectroscopy results point towards strong carbon corrosion after AST in $\mathrm{O}_{2}$, even when cycling at low potentials of 0.3-0.7 V vs. the reversible hydrogen electrode, while no corrosion occurred after any load cycling AST in Ar. The load cycling AST in $\mathrm{O}_{2}$ leads to the loss of a significant fraction of $\mathrm{FeN}_{\mathrm{x}}$ sites, as shown by energy dispersive $\mathrm{X}$-ray spectroscopy analyses, and to the formation of $\mathrm{Fe}$ oxides. The results support that the unexpected carbon corrosion occurring at such low potential in the presence of $\mathrm{O}_{2}$ is due to reactive oxygen species produced between $\mathrm{H}_{2} \mathrm{O}_{2}$ and $\mathrm{Fe}$ sites via Fenton reactions.
\end{abstract}

\section{Introduction}

The search for alternative decarbonized energies represents one of the most important challenges for the coming decades. In this context, hydrogen could help in the storage and conversion of renewable energies (solar, wind, geothermal) in an efficient and reliable manner. Proton exchange membrane fuel cells

Dr. K. Kumar, Dr. L. Dubau, Dr. M. Mermoux, Dr. F. Maillard Univ. Grenoble Alpes, Univ. Savoie Mont Blanc, CNRS, Grenoble INP', LEPMI, 38000 Grenoble (France)

Institute of Engineering Univ. Grenoble Alpes

E-mail: frederic.maillard@lepmi.grenoble-inp.fr

[*] Dr. F. Jaouen, Dr. J. Li

CNRS, Université de Montpellier, ENSCM

Institut Charles Gerhardt Montpellier UMR 5253

2 Place Eugène Bataillon, F-34095 Montpellier (France)

E-mail: frederic.jaouen@umontpellier.fr

\section{Dr. A. Zitolo}

Synchrotron SOLEIL

L'orme des Merisiers, BP 48 Saint Aubin, 91192 Gif-sur-Yvette (France)

Dr. J. Nelayah

Université de Paris, Laboratoire Matériaux et Phénomènes

Quantiques, CNRS, F-75013, Paris (France).

Supporting information for this article is given via a link at the end of the document.
(PEMFCs) are well positioned to become a cornerstone of the future renewable energy landscape but the significant amount of platinum $(\mathrm{Pt})$ required to accelerate the oxygen reduction reaction (ORR) kinetics casts a shadow on their economic attractiveness and long term sustainability [1]. The constraints associated with the use of precious metals are strong incentives for developing catalysts that are free of $\mathrm{Pt}$ group metals (PGM). Among few alternatives in acidic medium, the most mature sub-class of PGMfree ORR catalysts is prepared via the pyrolysis of metal atoms (Fe or $\mathrm{Co}$ ), nitrogen ( $\mathrm{N}$ ) and carbon (C) precursors. The most active sites in such materials have recently been identified, for the acidic medium, to be atomically dispersed metal cations ( $\mathrm{Fe}, \mathrm{Co}$ ) coordinated with nitrogen atoms, themselves embedded in stacked graphitic sheets $\left(\mathrm{MN}_{\mathrm{x}}\right.$ moieties). Whereas the nature of such active sites is very different from metallic nanoparticles in Ptbased catalysts, for both families of catalysts the overall mass activity toward ORR (MA) can be conceptually expressed as the mathematical product of the site density (SD, sites $\left.\cdot g_{\text {catalyst }}{ }^{-1}\right)$ and the intrinsic turnover frequency of a given site (TOF, electron/site/s at a given potential) ${ }^{[2]}$. While it is difficult to experimentally assess the SD and TOF values for such materials, also taking into account the possibility of multidunous $\mathrm{FeN}_{\mathrm{x}}$ site structure variations with different TOF values, the concept that overall activity is mainly guided by two independent parameters, SD and TOF, has been useful in rationalizing research and development efforts for maximizing the initial ORR activity of M$\mathrm{N}-\mathrm{C}$ materials in acidic medium. Knowledge of the SD in M-N-C cathodes is also important to guide the design of PEMFC cathodes, a few but very active $\mathrm{FeN}_{\mathrm{x}}$ sites contributing to the experimentally demonstrated higher mass-transport resistance of such PGM-free catalyst layers ${ }^{[3]}$.

Although important learnings and achievements have been reported on the $\mathrm{MN}_{\mathrm{x}}$ active sites, the fate of such sites after various time lapse and/or operating conditions in acidic media is still relatively underexplored, inhibiting rational approaches to improve their durability. Four main degradation mechanisms of $\mathrm{Fe}(\mathrm{Co})-\mathrm{N}-\mathrm{C}$ catalysts in acidic medium have been identified hitherto:

i) Mild surface oxidation of the carbon material (e.g by reactive oxygen species (ROS) following the formation of $\mathrm{H}_{2} \mathrm{O}_{2}$ by-product ${ }^{[4]}$ ), which hosts the $\mathrm{MN}_{\mathrm{x}}$ moieties, yielding unmodified $\mathrm{SD}$ but decreased TOF values due to a modification of the carbon surface properties with increasing content of oxygen functional groups [5], this type of 
deactivation being partially reversible upon reduction of the carbon surface.

Protonation of highly basic nitrogen groups, followed by anion adsorption ${ }^{[6]}$, which in ex-situ conditions (no electrochemical potential applied), was shown to be also partially reversible, while a fraction of the sites also irreversibly demetallated during acid wash. This phenomenon is particularly important for $\mathrm{NH}_{3}$-pyrolyzed catalysts or asprepared catalysts with highly basic $\mathrm{N}$-groups.

iii)

Demetallation of the $\mathrm{MN}_{\mathrm{x}}$ active sites in acid medium ${ }^{[7]}$, which has been recently shown to be accelerated when the electrochemical potential is decreased in the ORR range (0.3-0.8 V vs. the reversible hydrogen electrode, RHE) while demetallation is slowed down or insignificant in open circuit potential conditions (0.9-1.0 V vs. $\mathrm{RHE})$.

iv)

\begin{abstract}
Carbon corrosion and subsequent loss of $\mathrm{MN}_{\mathrm{x}}$ sites during accelerated stress tests (ASTs) mimicking uncontrolled and transient start/stop (ST/ST) of PEMFCs ${ }^{[7 c, 8]}$.
\end{abstract}

Since one or several of these deactivation/degradation mechanisms may occur in parallel during PEMFC operation, and due to time-consuming PEMFC experiments, ASTs have been developed for PEMFC and also for rotating disk electrode (RDE) studies. Inspired from the protocols previously developed for Ptbased catalysts, the stability of PGM-free catalysts has mostly been investigated hitherto using ASTs in inert-gas saturated liquid electrolyte at temperature $\leq 25^{\circ} \mathrm{C}[7 \mathrm{c}, 9]$. The main degradation phenomena expected for $\mathrm{Pt} / \mathrm{C}$ under such conditions are particle agglomeration or particle detachment, and $\mathrm{Pt}$ leaching for undercoordinated Pt atoms ${ }^{[10]}$. Survival of PGM-free active sites to the contact with acidic electrolyte is, compared to $\mathrm{Pt} / \mathrm{C}$ catalysts, a non-trivial and important topic that needs a solid verification before moving to the investigation of their stability in more realistic and aggressive conditions, e.g. under $\mathrm{O}_{2}$, implying the on-site production of $\mathrm{H}_{2} \mathrm{O}_{2}$, known to result in highly oxidizing $\mathrm{ROS}$ species, and additional related phenomena that do not occur in inert-gas saturated electrolyte.

In this work, we lean on the methodology reported in ref ${ }^{[7 c]}$ to investigate the fate of $\mathrm{FeN}_{\mathrm{x}}$ sites in the $\mathrm{Fe}-\mathrm{N}-\mathrm{C}$ catalyst that was found to be the most active and most stable one in our previous work, labelled $\mathrm{Fe}_{0.5} \mathrm{RP}$. The latter reached less than $25 \%$ loss in ORR mass activity after $30 \mathrm{k}$ load cycles between 0.6 and $1.0 \mathrm{~V}$ vs. RHE in $80^{\circ} \mathrm{C}$ deaerated sulphuric acid electrolyte. This AST is similar to the one defined by the United States Department of Energy (US DoE) for MEA testing in PEMFC (30 k square-wave load cycles between 0.60 and $0.95 \mathrm{~V}, 80^{\circ} \mathrm{C}$, in $\mathrm{H}_{2} / \mathrm{N}_{2}$ PEMFC), and the observed stability in such similar conditions matches the
US DoE target for PGM-free catalysts ( $<40 \%$ loss in initial mass activity after $30 \mathrm{k}$ load cycles). We here move to investigating the very same catalyst, this time in $\mathrm{O}_{2}$-saturated electrolyte, following the SD and TOF values with nitrite stripping methodology, the structural properties with transmission electron microscopy (TEM) and Raman spectroscopy and the chemical properties with energy dispersive $\mathrm{X}$-ray spectroscopy in scanning transmission electron microscopy (STEM/X-EDS). The presence of $\mathrm{O}_{2}$ is a priori not expected to play a direct role on electrochemical carbon corrosion, for which the reactant is water and not $\mathrm{O}_{2}$, but may indirectly trigger the formation of $\mathrm{H}_{2} \mathrm{O}_{2}$ via $2+2$ or $2 \times 2$ ORR mechanisms, the latter producing on-site hydroxyl $(\bullet \mathrm{OH})$ and hydroperoxo $(\bullet \mathrm{OOH})$ species via Fenton's reactions in acidic electrolyte ${ }^{[4 a, 9 d]}$. The possible role of $\mathrm{H}_{2} \mathrm{O}_{2}$ and ROS species was originally underlined by Lefevre et al. ${ }^{44 a}$. These ROS, in particular $\bullet \mathrm{OH}$, readily react with unsaturated aliphatic or aromatic compounds, yielding first oxygen-containing carbon surface groups (reversible deactivation by $\mathrm{H}_{2} \mathrm{O}_{2}$, Goellner et al. ${ }^{[4 \mathrm{~b}]}$ and Choi et al. ${ }^{[5]}$ ) and ultimately possibly resulting in the formation of volatile carbon corrosion products, $\mathrm{CO}$ and $\mathrm{CO}_{2}{ }^{[9 e]}$, leading in this case to metal leaching via destruction of $\mathrm{MN}_{\mathrm{x}}$ sites (irreversible degradation). More recently, using a kinetic model describing the degradation rate of PGM-free ORR catalysts, Yin et al. ${ }^{[11]}$ and Martinez et al. ${ }^{[12]}$ confirmed that peroxide and/or peroxide derived radicals are likely responsible for the performance loss in PEMFC devices. However, a detailed picture of the structural and chemical changes associated with $\mathrm{H}_{2} \mathrm{O}_{2}$ production/decomposition is still lacking. Beside this effect, it may be argued that binding of $\mathrm{O}_{2}$ to $\mathrm{MN}_{\mathrm{x}}$ sites during ORR may weaken the Metal- $\mathrm{N}$ bonds and accelerate demetallation relative to the same experimental conditions (electrochemical potential, electrolyte) but under an inert atmosphere ${ }^{[13]}$.

To gain insights into the possible role of ORR by-products on the degradation of non-PGM catalysts, we conducted mainly two different ASTs on a ZIF8-derived Fe-N-C catalyst composed of atomically-dispersed $\mathrm{Fe}$ atoms, either in $\mathrm{Ar}$ or $\mathrm{O}_{2}$-saturated acidic electrolyte. The two ASTs are: (i) a load-cycling (LC) protocol composed of 10,000 square cycles between 0.6 and $1.0 \mathrm{~V}$ vs. RHE (holding time $3 \mathrm{~s}$ at each potential) and (ii) a ST/ST protocol composed of 500 square cycles between 1.0 and $1.5 \mathrm{~V}$ vs. RHE (holding time $3 \mathrm{~s}$ at each potential). If not otherwise mentioned, ASTs were by default conducted at $80^{\circ} \mathrm{C}$. Temperature plays a key role in the rate of electrochemical carbon corrosion, and may also impact the rate at which metal cations demetallate from the $\mathrm{MN}_{\mathrm{x}}$ moieties ${ }^{[8]}$. Changes in chemistry, structure and morphology of the Fe-N-C catalyst were determined using a set of ex situ and in situ characterization techniques. The key result is that the $\mathrm{O}_{2}$ saturation of acidic electrolyte combined with load cycling leads to significantly enhanced loss of ORR activity compared to the same load cycling ASTs but performed in Ar-saturated electrolyte. This enhanced deactivation is correlated with enhanced demetallation of $\mathrm{FeN}_{\mathrm{x}}$ sites (significant loss of at least some of the $\mathrm{FeN}_{\mathrm{x}}$ sites) under such conditions, as a result of the combination of low potential during load cycling and $\mathrm{O}_{2}$ presence. The 
apparent overall loss of activity can thus be assigned to both i) a reduced number of $\mathrm{FeN}_{\mathrm{x}}$ active sites, and ii) a reduced turnover frequency of the $\mathrm{FeN}_{\mathrm{x}}$ sites that survived the $\mathrm{O}_{2}$ load cycling ASTs, as a result of surface oxidation of the carbon surface via Fenton type reaction, as previously demonstrated ex situ ${ }^{[5]}$. Depending on temperature and potential limits used during load cycling, Fe cations leached during these ASTs are either removed from the active layer or reprecipitate as Fe oxide nanoparticles. In contrast, during ST/ST protocol, the nature of the gas saturating the electrolyte does not play a significant role on the final ORR activity.

\section{Results}

\section{Physico-chemical characterization of $\mathrm{Fe}_{0.5} \mathrm{RP}$}

The Fe-N-C catalyst studied in this work, labelled $\mathrm{Fe}_{0.5} \mathrm{RP}$, was synthesized by ramp pyrolysis up to $1050^{\circ} \mathrm{C}$ in $\mathrm{Ar}$ of a mix comprising ZIF-8, Fe(II) acetate and phenanthroline (see Supporting Information). Compared to the initial work ${ }^{[14]}$, a ramp instead of flash pyrolysis was applied here, ${ }^{[15]}$ as it was shown to result in higher activity and stability in acid medium ${ }^{[7 \mathrm{c}]}$. The weight loss during pyrolysis is ca. 70 wt. \% and Fe content (measured by $\mathrm{X}$-ray fluorescence) in $\mathrm{Fe}_{0.5} \mathrm{RP}$ ca. 1.3 wt. \%. Low magnification and high-resolution TEM images in various locations (Figures 1ab) could not detect Fe clusters. The atomically dispersed nature of Fe was confirmed by extended X-ray absorption fine structure (EXAFS) spectroscopy (Figure 1c) showing peaks at distances of 1.4 and $2.4 \AA$, assigned to $\mathrm{Fe}-\mathrm{N}$ and $\mathrm{Fe}-\mathrm{C}$ backscatterings due to the first and second coordination spheres in $\mathrm{FeN}_{\mathrm{x}} \mathrm{C}_{\mathrm{y}}$ moieties, respectively. Also, the presence in the ${ }^{57} \mathrm{Fe}$ Mössbauer spectrum measured at $5 \mathrm{~K}$ of only two quadrupole doublets labelled $D 1$ and $D 2$, fingerprints of $\mathrm{FeN}_{\mathrm{x}} \mathrm{C}_{\mathrm{y}}$ moieties in different oxidation and spin states, ${ }^{[16]}$ (Figure 1d) confirms the absence of Fe aggregates in $\mathrm{Fe}_{0.5} \mathrm{RP}$.
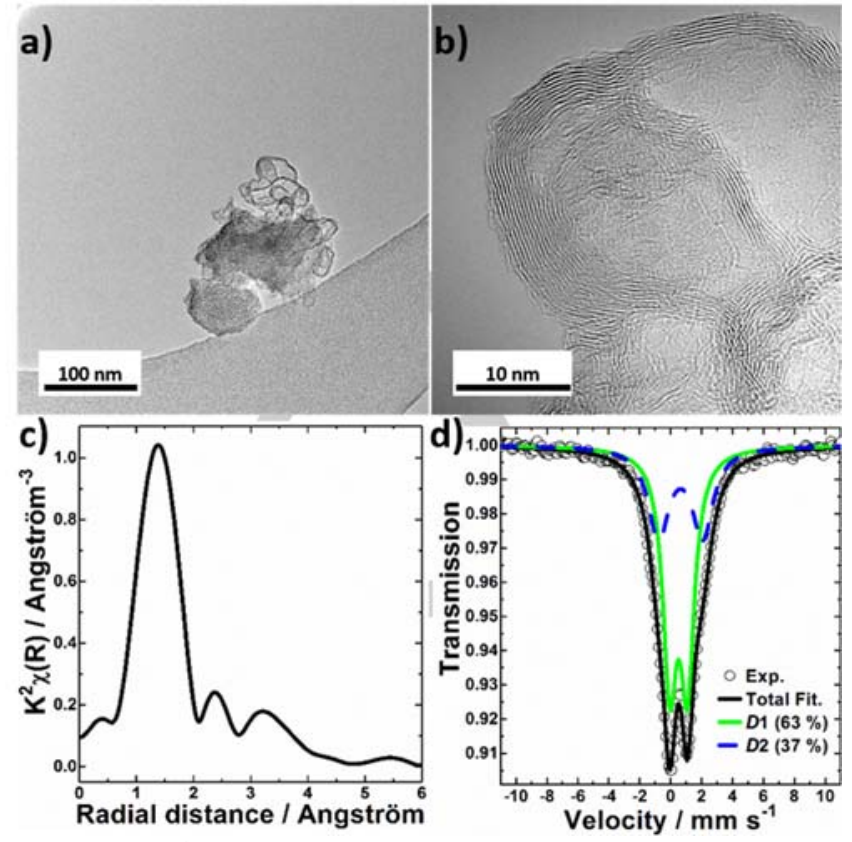

Figure 1. Physico-chemical characterizations of $\mathrm{Fe}_{0.5} \mathrm{RP}$. (a) Low-magnification and (b) high-resolution transmission electron microscopy images (c) Magnitude of Fourier transform $\mathrm{k}^{2} \mathrm{X}(R) \mathrm{Fe} K$-edge EXAFS spectrum. (d) ${ }^{57} \mathrm{Fe}$ Mössbauer transmission spectrum at $5 \mathrm{~K}$ and its fitting with $D 1$ and $D 2$ doublets. The fitted isomer shifts for $D 1$ and $D 2$ are 0.50 and $0.64 \mathrm{~mm} \mathrm{~s}^{-1}$, respectively, and the fitted quadrupole splittings 1.14 and $2.86 \mathrm{~mm} \mathrm{~s}^{-1}$, respectively.

Effect of $\mathrm{Ar}$ and $\mathrm{O}_{2}$ saturating gas on the electrocatalytic properties after AST protocols

The normalized MA at $E=0.80 \mathrm{~V}$ vs. RHE of $\mathrm{Fe}_{0.5} \mathrm{RP}$ before and after ASTs conducted either in $\mathrm{Ar}$ - or $\mathrm{O}_{2}$-saturated acidic electrolyte are shown in Figure 2a (polarisation curves were corrected from pseudocapacitive current, Ohmic drop and $\mathrm{O}_{2}$ diffusion in solution). Normalized MA values at $E=0.85 \mathrm{~V} v$ s. RHE are reported in Figure $\mathbf{S 1}$ while absolute MA values and halfwave potentials are reported in Table S1 and Table S2. The MA at $0.85 \mathrm{~V}$ of $\mathrm{Fe}_{0.5} \mathrm{RP}$ is comparable to that of state of the art Fe-N$\mathrm{C}$ catalysts, especially taking into account it was not subjected to $\mathrm{NH}_{3}$ pyrolysis (Table S2 and Ref. ${ }^{[17]}$ ). Limited ORR activity decrease is observed after the Ar-LC AST (-16\%), and assigned to demetallation from a minor fraction of acid-unstable surface $\mathrm{FeN}_{\mathrm{x}}$ moieties present in the pristine $\mathrm{Fe}_{0.5} \mathrm{RP}$ sample (not subjected to any acid leaching during synthesis), in agreement with our former results ${ }^{[7 c]}$. Significantly higher ORR activity decrease is observed (-66\%) after the $\mathrm{O}_{2}$-LC protocol. This is paralleled by obvious increase of the cyclic voltammogram (CVs) capacitive current after the $\mathrm{O}_{2}$-LC protocol (Figure S2) vs. Ar-LC (see Figure $\mathrm{S} 3$ in our ref ${ }^{[7 \mathrm{c}]}$ ). This increased capacitive signal can be assigned either to increased pseudocapacitance via e.g. the introduction of oxygen functional groups, or increased carbon surface area as a result of formation of novel pores and or rougher carbon surface. In contrast, the nature of the saturating gas had little influence on final ORR mass activities after ST/ST protocols, revealing that it is the combination of LC protocol with the 
presence of $\mathrm{O}_{2}$ that leads to enhanced deactivation that is $\mathrm{O}_{2-}$ specific. ORR activity decrease may be the result of decreased $\mathrm{SD}$, decreased TOF, or a combination of both factors. The general observation that $\mathrm{O}_{2}$ and LC mode are both necessary for enhanced activity loss suggests that the additional degradation mechanism in such conditions may be due to i) the ORR process itself on $\mathrm{FeN}_{\mathrm{x}}$ sites $\left(\mathrm{O}_{2}\right.$ binding on $\mathrm{Fe}^{2+}$ centres, destabilizing the latter during ORR) or ii) the ORR leading to $\mathrm{H}_{2} \mathrm{O}_{2}$ by-product, and the latter forming ROS by Fenton type reaction. Mechanism i) would simply lead to a loss of active sites. For ii), ROS species could in turn lead first to mild and reversible surface oxidation of carbon that induces a decreasing TOF of $\mathrm{FeN}_{\mathrm{x}}$ sites, but no destruction of these sites ${ }^{[5]}$. Upon prolonged cycling, ROS species may lead to irreversible carbon corrosion leading in turn to the destruction of a significant fraction of $\mathrm{FeN}_{\mathrm{x}}$ sites, this mechanism being similar to what is observed in ST/ST conditions [7c, 18].

To gain more insights into the reasons for the decreased ORR activity during these ASTs, the SD of the fresh and aged $\mathrm{Fe}_{0.5} \mathrm{RP}$ catalysts was determined using the nitrite stripping method introduced by Malko et al. [2]. This method relies on the chemisorption of nitrite ions onto the $\mathrm{Fe}^{2+}$ centres of $\mathrm{FeN}_{\mathrm{x}}$ sites at $\mathrm{pH} 5.2$, followed by reductive stripping, the charge of which directly leads to the SD value and then, by combination with the change in MA measured at $\mathrm{pH} 5.2$ before/after nitrite chemisorption, leads to the average TOF values (see Supporting Information). We note that, while this method has been applied to different as-synthesized Fe-N-C catalysts ${ }^{[2,19]}$, it has not yet been applied to aged Fe-N-C catalysts, which may lead to unexpected complexities, as shown and discussed later. Figure $\mathbf{2 b}$ and Figure 2c display the normalized values before/after ASTs of SD and TOF, respectively. CVs and ORR polarization curves before, during and after nitrite adsorption are also shown in Figure S3. After Ar-LC, the SD and TOF values were nearly unchanged (within the error bar), which is consistent with the mild changes of MA observed in these experimental conditions, suggesting little change of the catalyst structure, surface chemistry and type of active sites (note that MA values were determined at $\mathrm{pH} 1.0$ and loading $0.8 \mathrm{mg}_{\text {powder }} \mathrm{cm}^{-2}$ while $\mathrm{SD}$ and TOF values were measured at $\mathrm{pH} 5.2$ and loading $0.3 \mathrm{mg}_{\text {powder }} \mathrm{cm}^{-2}$ ). On the contrary, after the $\mathrm{O}_{2}-\mathrm{LC}$ protocol, the $\mathrm{SD}$ value surprisingly increased $(+40 \%)$ and the average TOF value significantly decreased $(-50 \%)$. One may think of at least three explanations for increased SD value: i) some surface $\mathrm{FeN}_{\mathrm{x}}$ sites that existed in the fresh catalyst but that were not sensed by the nitrite method became active for nitrite adsorption after the $\mathrm{O}_{2}-\mathrm{LC}$ protocol, ii) more $\mathrm{FeN}_{\mathrm{x}}$ sites are exposed to the surface after $\mathrm{O}_{2}-\mathrm{LC}$, iii) more $\mathrm{Fe}$ atoms are exposed to the surface after $\mathrm{O}_{2}-\mathrm{LC}$, but not necessarily all in the form of $\mathrm{FeN}_{\mathrm{x}}$ sites. Note that we can rule out that increased $\mathrm{SD}$ after $\mathrm{O}_{2}-\mathrm{LC}$ might be the result of the formation of specific oxygen-containing groups created on the carbon surface during the $\mathrm{O}_{2}-\mathrm{LC}$ AST, since no nitrite strippping charge was measured after $\mathrm{O}_{2}-\mathrm{LC}$ on a $\mathrm{N}$-doped carbon (free of $\mathrm{FeN}_{x}$ sites, and labelled NC) material (Figure S4). For hypothesis i), reduction of $\mathrm{Fe}^{3+} \mathrm{N}_{\mathrm{x}}$ sites into $\mathrm{Fe}^{2+} \mathrm{N}_{\mathrm{x}}$ sites during load cycling may explain an increased SD. However, it does not appear logical that a switch from $\mathrm{Ar}$ to $\mathrm{O}_{2}$ saturating gas would increase the SD value measured by nitrite stripping method in this hypothesis. For hypothesis ii), some support is provided by the increased $\mathrm{CV}$ signal after the $\mathrm{O}_{2}$-LC protocol. Carbon corrosion could have exposed more $\mathrm{FeN}_{\mathrm{x}}$ sites to the surface. It can however be expected that it would also have led to the destruction of at least a fraction of the initial $\mathrm{FeN}_{\mathrm{x}}$ active sites. Hypothesis iii) seems therefore more attractive to explain all experimental phenomena, i.e. increased SD, increased pseudocapacitive current and strong ORR activity decrease. More information is however needed on the fate of $\mathrm{FeN}_{\mathrm{x}}$ sites during $\mathrm{O}_{2}$ - $\mathrm{LC}$ and on what $\mathrm{Fe}$ species the nitrite stripping method probes on aged $\mathrm{Fe}_{0.5} \mathrm{RP}$ catalyst. As the next section on physico-chemical characterisation will show, $\mathrm{FeO}$ particles are detected after the $\mathrm{O}_{2}-\mathrm{LC}$ protocol.

To unveil whether the nitrite stripping method is sensitive to $\mathrm{Fe}$ oxides, we deposited $10 \mathrm{wt} \% \mathrm{Fe}_{2} \mathrm{O}_{3}$ commercial nano-oxides on the $\mathrm{N}$-doped carbon, and we label it $\mathrm{Fe}_{2} \mathrm{O}_{3} / \mathrm{NC}$. The $\mathrm{NC}$ was prepared as $\mathrm{Fe}_{0.5} \mathrm{RP}$ except that no $\mathrm{Fe}$ acetate was used. TEM images of the $\mathrm{Fe}_{2} \mathrm{O}_{3} / \mathrm{NC}$ catalyst shown in Figure S5a-b display particles in the range 20 to $150 \mathrm{~nm}$. Room temperature Mössbauer spectroscopy identifies one sextet that can be assigned to $\mathrm{Fe}_{2} \mathrm{O}_{3}$ particles (Figure S5c). The nitrite stripping method was then applied to $\mathrm{Fe}_{2} \mathrm{O}_{3} / \mathrm{NC}$. The $\mathrm{CVs}$ and ORR polarization curves before, during and after nitrite adsorption are shown in Figure S6. The results demonstrate that nitrite ions probe the $\mathrm{Fe}_{2} \mathrm{O}_{3}$ particles and that such particles have non-zero ORR activity. Slightly higher SD but much lower TOF was found for $\mathrm{Fe}_{2} \mathrm{O}_{3} / \mathrm{NC}$ (with 10 wt. \% Fe oxide) relative to $\mathrm{Fe}_{0.5} \mathrm{RP}$ (ca. $1.3 \mathrm{wt}$. \% Fe content) (Figure S5d). These striking results demonstrate that the SD value measured by the nitrite stripping method can actually include not only ferrous centres from $\mathrm{FeN}_{\mathrm{x}}$ sites but also from other structures. It is therefore important to characterise in-depth the aged $\mathrm{Fe}_{0.5} \mathrm{RP}$ catalysts before further discussing the SD values after AST protocols shown in Figure $\mathbf{2 b}$. Likewise, the average TOF values after the different AST protocols (Figure 2c) must be considered with caution at this stage, since they are derived from the differential MA value measured before and after nitrite adsorption divided by the SD value. If some of the aged $\mathrm{Fe}_{0.5} \mathrm{RP}$ catalysts contain both $\mathrm{FeN}_{\mathrm{x}}$ sites and $\mathrm{Fe}$ oxide particles, the $\mathrm{SD}$ number actually overestimates the number of surface-located $\mathrm{FeN}_{\mathrm{x}}$ sites after AST. In turn, the average TOF value then underestimates the TOF of those $\mathrm{FeN}_{\mathrm{x}}$ sites that survived the AST. With this in mind, Figure 2c shows that the average TOF value after all AST protocols significantly decreased, except after the Ar-LC protocol. The average TOF values after the $\mathrm{O}_{2}$ - LC, Ar- ST/ST and $\mathrm{O}_{2}-\mathrm{ST} / \mathrm{ST}$ protocols are similar. These protocols however lead to different Fe speciation after AST, as shown in the next section. 

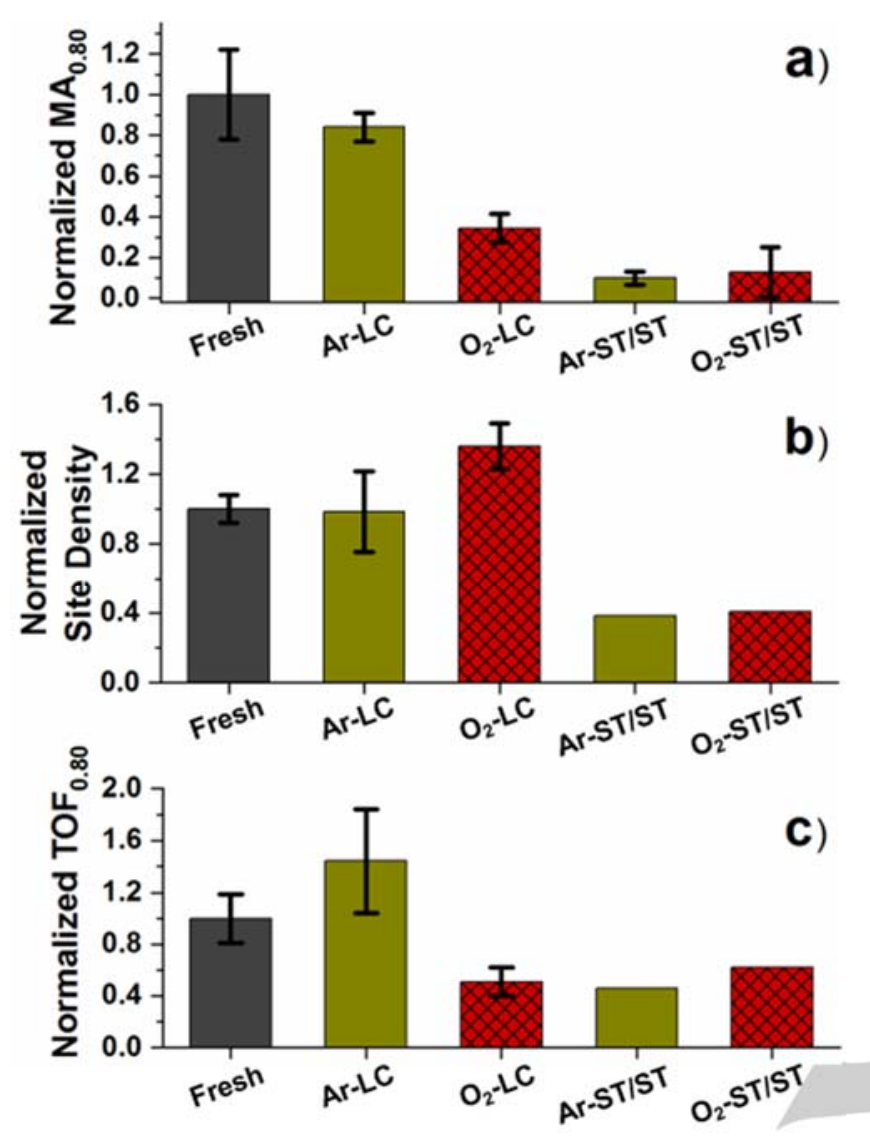

Figure 2. ORR activity at $\mathrm{pH} 1$, site density and turnover frequency at $\mathrm{pH} 5.2$ determined by nitrite striping method before/after Ar-LC, $\mathrm{O}_{2}-\mathrm{LC}, \mathrm{Ar}-\mathrm{ST} / \mathrm{ST}$ and $\mathrm{O}_{2}-\mathrm{ST} / \mathrm{ST}$. (a) Normalized mass activity of $\mathrm{Fe}_{0.5} \mathrm{RP}$ at $E=0.8 \mathrm{~V}$ vs. RHE. The mass activity towards the ORR was measured in $\mathrm{O}_{2}$-saturated $0.1 \mathrm{M} \mathrm{H}_{2} \mathrm{SO}_{4}$ at $1600 \mathrm{rpm}, T=25^{\circ} \mathrm{C}$ and at a scan rate $v=5 \mathrm{mV} \mathrm{s}^{-1}$. The catalyst loading was $800 \mu \mathrm{g} \mathrm{cm}^{-2}$. (b) Normalized site density of $\mathrm{Fe}_{0.5} \mathrm{RP}$ catalyst. (c) Normalized TOF of $\mathrm{Fe}_{0.5} \mathrm{RP}$ catalyst at $E=0.8 \mathrm{~V}$ vs. RHE. The site density and the TOF value were determined in acetate buffer at $\mathrm{pH} 5.2$ and the catalyst loading was 300 $\mu \mathrm{g} \mathrm{cm}^{-2}$. All LC-protocol experiments were repeated at least twice and the error bars correspond to the standard deviation of the measurements.

To shed light on how the presence of $\mathrm{O}_{2}$ during the $\mathrm{LC}$ protocol may have triggered increased deactivation compared to the same LC but under argon, rotating ring disk electrode (RRDE) measurements were performed to quantify $\mathrm{H}_{2} \mathrm{O}_{2}$ formed during ORR. Peroxide was in fact recently shown to deactivate Fe-N-C via heterogeneous non-electrochemical reaction, even in the absence of ORR ${ }^{[5]}$. Three different $\mathrm{Fe}_{0.5} \mathrm{RP}$ loadings were used: 100,200 and $400 \mu \mathrm{g} \mathrm{cm}{ }^{-2}$. Figure $\mathrm{S} 7$ shows that the $\% \mathrm{H}_{2} \mathrm{O}_{2}$ steeply increased with decreasing loading. A low catalyst loading is known to be more representative of the true selectivity of M-N$\mathrm{C}$ catalysts, high loadings showing lower apparent $\% \mathrm{H}_{2} \mathrm{O}_{2}$ due to chemical and/or electrochemical decomposition of peroxide through the active layer, decreasing the amount of peroxide detected at the ring electrode. ${ }^{[7 b]}$ While this effect has been reported previously for various Fe-N-C catalysts ${ }^{[7 b, 20]}$, the effect of catalyst loading on the activity before/after $\mathrm{O}_{2}-\mathrm{LC}$ has not yet been reported. Figure $\mathbf{S 8}$ shows that the normalized MA of
$\mathrm{Fe}_{0.5} \mathrm{RP}$ after the $\mathrm{O}_{2}$-LC protocol continuously increased with decreasing $\mathrm{Fe}_{0.5} \mathrm{RP}$ loading. In other words, $\mathrm{Fe}_{0.5} \mathrm{RP}$ deactivates less in a thin layer than in a thick layer during $\mathrm{O}_{2}-\mathrm{LC}$ protocol. This trend can be explained by the faster removal of peroxide in thin layers, mitigating the chemical reaction of the produced peroxide with Fe-based active sites.

While $\mathrm{H}_{2} \mathrm{O}_{2}$ formed during ORR is a recognized additional source of deactivation for $\mathrm{Fe}-\mathrm{N}-\mathrm{C}$ catalysts during load cycling under $\mathrm{O}_{2}-$ vs. under Ar-saturation, electrochemical carbon corrosion triggered by electrochemical potential is another possible source of degradation. A priori, one would not expect enhanced electrochemical carbon corrosion during load cycling in $\mathrm{O}_{2}$ vs. in $\mathrm{Ar}$, because $\mathrm{O}_{2}$ is not formally present in the reaction equation for electrochemical carbon corrosion. However, experimentally, we observed a stronger $\mathrm{CV}$ signal after $\mathrm{O}_{2}$-LC (Figure S2a) than after Ar-LC (Figure S3 in our previous work ${ }^{[7 \mathrm{c}]}$ ), suggesting increased pseudocapacitance or enhanced corrosion in presence of $\mathrm{O}_{2}$. For this reason, we decided to investigate the effect of temperature and potential-range on the activity after $\mathrm{O}_{2}$-LC protocol, both being parameters controlling the rate of classical carbon corrosion. As shown by Figure S9a, the normalized MA value after $\mathrm{O}_{2}-\mathrm{LC}$ performed at $25^{\circ} \mathrm{C}$ was slightly higher than that after $\mathrm{O}_{2}-\mathrm{LC}$ performed at $80^{\circ} \mathrm{C}(0.66$ vs. 0.40$)$. This slight difference is not in line with the huge increase in the kinetics of the classical electrochemical carbon corrosion from 25 to $80^{\circ} \mathrm{C}$ (ca. $\times 20$ to $\times 40$ ) reported by us previously for Fe-N-C and Pt/C catalysts [9b, 18a, 21]. Similarly, changing the potential range from 0.6-1.0 V vs. RHE to 0.5-0.9 V vs. RHE or even 0.3-0.7 V vs. RHE during $\mathrm{O}_{2}-\mathrm{LC}$ at $80^{\circ} \mathrm{C}$ did not significantly change the final ORR activity (Figure S9a), suggesting that a higher electrochemical potential (up to $1.0 \mathrm{~V}$ vs. RHE) does not lead to strongly increased degradation during $\mathrm{O}_{2}$-LC. Again, this is in contrast with results that would be expected if the deactivation during $\mathrm{O}_{2}-\mathrm{LC}$ was controlled by classical electrochemical carbon corrosion. Figure S9b and Figure S9c show that the two different $\mathrm{O}_{2}$-LCs performed at $80^{\circ} \mathrm{C}$ (different upper and lower limits of potentials) all lead to increased SD and decreased TOF values (normalized vs. fresh material), respectively. The $\mathrm{O}_{2}-\mathrm{LC}$ performed at $25^{\circ} \mathrm{C}$ however resulted in normalized SD and TOF values much closer to unity (i.e. closer to values found in the fresh catalyst). The next section will show that temperature plays a role on the fate of Fe species that leach out during $A S T$, the normalized $S D$ values $>1$ being related to reprecipitation of leached $\mathrm{Fe}$ cations from $\mathrm{FeN}_{\mathrm{x}}$ sites as $\mathrm{Fe}$ oxides.

\section{Physico-chemical characterization of $\mathrm{Fe}_{0.5} \mathrm{RP}$ before/after AST protocols}

TEM images of $\mathrm{Fe}_{0.5} \mathrm{RP}$ after the different ASTs are displayed in Figure 3. Whereas Figure 3a shows no Fe or Fe oxide particle after the Ar-LC protocol, Figures $\mathbf{3 b}$-c evidence the presence of many particles of $10-50 \mathrm{~nm}$ size after the $\mathrm{O}_{2}$-LC protocol. In contrast, after the ST/ST protocol at $80^{\circ} \mathrm{C}$, no particles were observed (not shown). The local Fe content on the particle-free 
areas, estimated by X-EDS analyses, decreased by only ca. $19 \%$ after Ar-LC but by $83 \%$ after $\mathrm{O}_{2}$-LC (Figure 3d). The local Fe content after ST/ST protocol probed by local X-EDS analyses (at least five different circular regions of $100 \mathrm{~nm}$ diameter) decreased by ca. $70 \%$, regardless of the saturating gas atmosphere, (Figure 3d). Note that these analyses remain local and reflect the Fe content on particle-free areas, and cannot be generally assimilated with the average $\mathrm{Fe}$ content, especially after $\mathrm{O}_{2}-\mathrm{LC}$. XRD measurements performed on the fresh and aged $\mathrm{Fe}_{0.5} \mathrm{RP}$ catalysts revealed additional diffraction peaks after $\mathrm{O}_{2}-\mathrm{LC}$ that can be assigned to $\mathrm{FeO}$ (PDF 00-046-1312, Figure 3e) or $\mathrm{Fe}_{0.9} \mathrm{O}$ (würstite, PDF 04-001-9267). Spatially-resolved STEM/X-EDS elemental maps displayed in Figure $\mathbf{S 1 0}$ confirmed the simultaneous presence of $\mathrm{O}, \mathrm{C}$ and $\mathrm{Fe}$ in the nanoparticles observed after the $\mathrm{O}_{2}$-LC protocol. This does not exclude the presence of other Fe crystallites with (sub)-nano-size, that would be below the detection limit of XRD and STEM/X-EDS. The presence of $\mathrm{FeO}$ may appear at first surprising since the stable form of $\mathrm{Fe}$ at $\mathrm{pH}<2$ is solvated $\mathrm{Fe}^{2+}$ or $\mathrm{Fe}^{3+}$, depending on the electrochemical potential (below or above ca. $0.77 \mathrm{~V}$ vs. RHE, respectively) ${ }^{[22]}$. However, at potentials $>$ ca. $0.77 \mathrm{~V}$ vs. RHE, $\mathrm{FeO} / \mathrm{Fe}_{2} \mathrm{O}_{3}$ particles can also be thermodynamically stable at $\mathrm{pH}$ $>2$, and the position of the vertical $\mathrm{pH}$ limit in the Fe Pourbaix diagram strongly depends on the Fe oxide particle size, with nanoparticles shifting the position of that line toward more acidic $\mathrm{pH}$ values $\left(\mathrm{pH}\right.$ limit below 1.8 at temperature close to $100^{\circ} \mathrm{C},{ }^{[23]}$ such as that employed in this study). No diffraction patterns that may be assigned to Fe-rich phases were seen on the XRD after the Ar-LC, Ar-ST/ST or $\mathrm{O}_{2}$-ST/ST, in line with TEM analyses.

The carbon structure was then investigated by Raman spectroscopy. As shown by Figure S11, the $D_{1}\left(1350 \mathrm{~cm}^{-1}\right)$ and $G$ $\left(1580 \mathrm{~cm}^{-1}\right)$ bands considerably narrowed after the $\mathrm{O}_{2}$-LC protocol, but remained nearly unchanged after the Ar-LC protocol. Similarly, the intensity of the $D_{3}$ band $\left(1495 \mathrm{~cm}^{-1}\right)$ decreased after the $\mathrm{O}_{2}-$ LC but remained unaffected after the Ar-LC protocol. We also notice in Figure $\mathbf{3 f}$, the emergence of three different bands, located at 2710, 2920 and $3240 \mathrm{~cm}^{-1}$, in the second-order Raman spectrum after the $\mathrm{O}_{2}-\mathrm{LC}$ protocol. These three bands are attributed to a combination of $D_{1}$ and $G$ bands overtone ${ }^{[9 c, 24]}$, and suggest preferential corrosion of the structurally-disordered carbon domains present in the $\mathrm{Fe}_{0.5} \mathrm{RP}$ catalyst during $\mathrm{O}_{2}-\mathrm{LC}$, leaving behind the more graphitic domains, in agreement with former findings ${ }^{[7 c]}$. Note also that the Raman spectra after the $\mathrm{O}_{2-}$ LC and the $\mathrm{O}_{2}$-ST/ST protocols are similar, thus supporting our hypothesis that carbon corrosion was intense during the $\mathrm{O}_{2}-\mathrm{LC}$ protocol.

TEM was also used to analyse the aged $\mathrm{Fe}_{0.5} \mathrm{RP}$ catalysts after load cycling in $\mathrm{O}_{2}$ atmosphere but at $25^{\circ} \mathrm{C}$ (Figure S12a) and after load cycling in $\mathrm{O}_{2}$ atmosphere at $80^{\circ} \mathrm{C}$ but in the potential range of $0.5-0.9 \mathrm{~V}$ vs. RHE (Figure S12b). In contrast to $\mathrm{O}_{2}-\mathrm{LC}$ at $80^{\circ} \mathrm{C}$ (Fe oxide particles observed), $\mathrm{O}_{2}-\mathrm{LC}$ at $25^{\circ} \mathrm{C}$ does not lead to the formation of $\mathrm{Fe}$ oxide particles. In the latter case, the nitrite stripping method probes only $\mathrm{FeN}_{\mathrm{x}}$ sites after the AST, and the very low decrease of SD number after $\mathrm{O}_{2}$ - $\mathrm{LC}$ at $25^{\circ} \mathrm{C}$ reported in Figure S9b $(-10 \%)$ suggests that the decrease in MA after the same AST (-34\%) (Figure S9a) can mostly be assigned to a reduced TOF of otherwise unmodified $\mathrm{FeN}_{\mathrm{x}}$ sites (i.e. same phenomenon as seen for ex-situ peroxide treatment). 

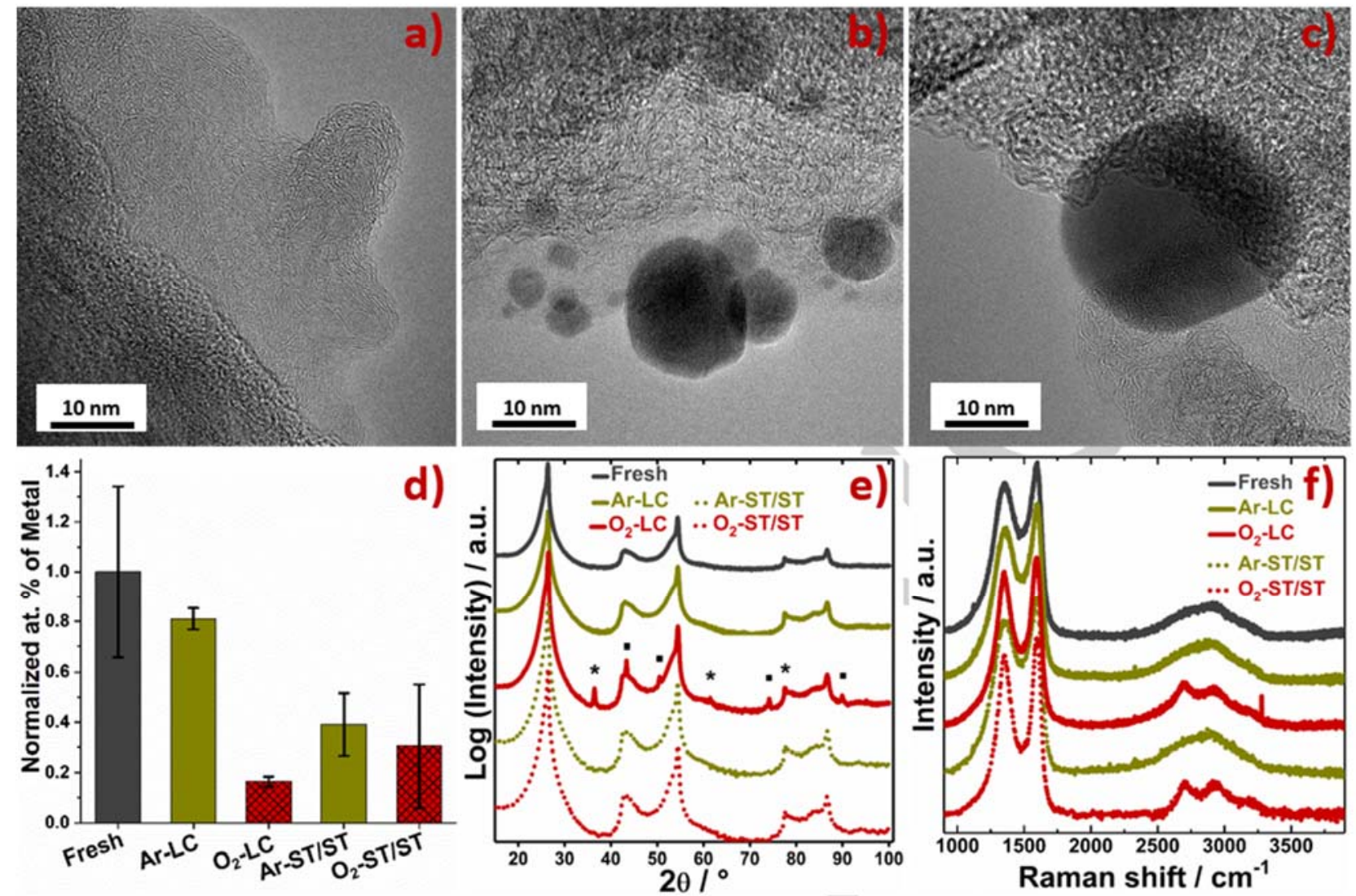

Figure 3. Structural and physico-chemical characterizations of the catalytic layer before and after the different ASTs at $80{ }^{\circ} \mathrm{C}$. TEM images after (a) Ar-LC and (bc) $\mathrm{O}_{2}$-LC. (d) Normalized local Fe content according to X-EDS analyses on particle-free areas after the different ASTs. Error bars were obtained from at least six measurements. Figure $3 \mathrm{~d}$ is a local analysis, and cannot be generally assimilated with the average Fe content, especially after $\mathrm{O}_{2}$-LC. (e) $\mathrm{X}$-ray powder diffraction patterns before and after the different ASTs. Three main crystallite phases can be indexed: (") Fe cubic Fm-3m (PDF 04-002-3692), ( $)$ iron oxide FeO cubic Fm$3 \mathrm{~m}$ (PDF 00-046-1312) and graphitic C (PDF 00-056-0159), the latter not indexed in the figure. (f) Raman spectra before and after the different ASTs.

\section{Discussion}

Following the electrochemical and physico-chemical characterizations, we here discuss all the results together to draw conclusions on the main degradation mechanisms occurring in the different ASTs, and focusing on load cycling under $\mathrm{O}_{2}$, in different conditions (temperature, lower and higher potential limits during the AST). Coming back to Figure 2, the trends of MA, SD and TOF can now be explained in more detail. After Ar-LC, the very small change in MA, SD and TOF values can simply be explained by the fact that the vast majority of $\mathrm{FeN}_{\mathrm{x}}$ sites survived the AST. The post-AST XRD and TEM analyses do not reveal any $\mathrm{Fe}$ or Fe oxide particles, while local X-EDS analyses indicate a same content of $\mathrm{FeN}_{\mathrm{x}}$ sites as in the fresh catalyst, locally (Figure 3d). Moreover, no change in the carbon structure was observed (Figure $3 \mathrm{e}$ and Figure $3 \mathrm{f})$. In contrast, after $\mathrm{O}_{2}$ - $\mathrm{LC}\left(80^{\circ} \mathrm{C}\right)$, Figure 2 showed a decrease in $M A$, and an increase in $S D$, while post-AST XRD, TEM and STEM/X-EDS identify the presence of Fe oxide nanoparticles (Figure 3 e and Figure S10). These oxide particles originate from the leaching of $\mathrm{Fe}$ from $\mathrm{FeN}_{\mathrm{x}}$ sites, reprecipitating as $\mathrm{Fe}$ oxides on the $\mathrm{N}$-doped carbon surface, in those cycling conditions. If only $\mathrm{FeN}_{\mathrm{x}}$ sites that were located on the top surface in the fresh catalyst had leached and precipitated, one would expect, at most (if all $\mathrm{Fe}$ atoms of Fe oxides are nitriteaccessible, which is not the case), a same SD value before and after the AST, since we showed that the nitrite stripping method is sensing both $\mathrm{FeN}_{\mathrm{x}}$ sites and $\mathrm{Fe}$ oxides. However, the SD value is significantly higher after $\mathrm{O}_{2}$ - $\mathrm{LC}\left(80^{\circ} \mathrm{C}\right),+40 \%$. This can be explained only if more $\mathrm{Fe}$ atoms are exposed on the surface after the AST than initially. In turn, this implies that some Fe atoms initially situated in the bulk (as $\mathrm{FeN}_{\mathrm{x}}$ sites) were brought to the surface during the AST. This is possible only if carbon corrosion occurred, and evidence is given for this by the increased CV signal (Figure S2a) and narrower Raman bands after $\mathrm{O}_{2}$ - $\mathrm{LC}$ (Figure S11b). The higher SD value after $\mathrm{O}_{2}-\mathrm{LC}$ is thus an artifact, and not representative for the number of $\mathrm{FeN}_{\mathrm{x}}$ sites remaining after this AST. Similarly, the TOF reported after $\mathrm{O}_{2}$-LC is not representative of the TOF of $\mathrm{FeN}_{\mathrm{x}}$ sites that survived the AST, due to presence of $\mathrm{Fe}$ oxides after $\mathrm{O}_{2}-\mathrm{LC}$ performed at $80^{\circ} \mathrm{C}$. The true $\mathrm{SD}$ value of $\mathrm{FeN}_{\mathrm{x}}$ sites after $\mathrm{O}_{2}-\mathrm{LC}$ at $80^{\circ} \mathrm{C}$ is therefore lower than the value reported in Figure $\mathbf{2 b}$, and the true TOF higher than reported in Figure 2c, for this AST. Our results thus identify the conditions that lead to deactivation/degradation of Fe-N-C materials in PEMFC cathode conditions, with complex and 
unexpected phenomena occurring during load cycling in the presence of $\mathrm{O}_{2}$. While we use the terminology of carbon corrosion to describe the structural changes occurring to carbon in those conditions, it should be underlined that this corrosion mechanism is quite distinct from the better known electrochemical carbon corrosion occurring during ST/ST protocols. While the latter is highly dependent on electrochemical potential, the results shown here reveal that this is not the case for the carbon corrosion occurring during load cycling under $\mathrm{O}_{2}$ atmosphere on this $\mathrm{Fe}-\mathrm{N}$ $\mathrm{C}$ catalyst. For example, performing the same load cycling in $\mathrm{O}_{2}$ at 25 or $80^{\circ} \mathrm{C}$ lead to quite similar loss in MA, while moving the lower and upper potential limits during the load cycling (from 0.3 to $0.6 \mathrm{~V}$ and 0.7 to $1.0 \mathrm{~V}$, respectively) did not impact the extent of degradation of the material (Figure S9a). In parallel, we verified that the peroxide produced during ORR and the electrode thickness play an important role in the extent of MA loss during the load cycling in $\mathrm{O}_{2}$ (see Figure $\mathbf{S 7}$ and Figure S8). It therefore seems that $\mathrm{H}_{2} \mathrm{O}_{2}$ and/or ROS formed in situ on the $\mathrm{FeN}_{\mathrm{x}}$ sites during ORR are causing not only mild oxidation of the surface (as reported for ex situ treatment of Fe-N-C by $\mathrm{H}_{2} \mathrm{O}_{2}$, chemically) but also irreversible carbon corrosion, i.e. forming volatile products $\mathrm{CO}$ and $\mathrm{CO}_{2}$, leading to the formation of new pores (increased carbon area), but also to the destruction of a fraction of the $\mathrm{FeN}_{\mathrm{x}}$ active sites. In contrast to classical electrochemical carbon corrosion, this phenomenon proceeds at significant rate even in the moderately high potential region of $0.6-1.0 \mathrm{~V}$ and even in the region of 0.3-0.7 V vs. RHE (Figure S9). The results also show that the Fe cations leached from $\mathrm{FeN}_{\mathrm{x}}$ can either reprecipitate as Fe oxides at $80^{\circ} \mathrm{C}$, but seem to diffuse away in the electrolyte at $25^{\circ} \mathrm{C}$ (Figure S12). The absence of Fe oxide particles after load cycling in $\mathrm{O}_{2}$ at $25^{\circ} \mathrm{C}$, a temperature used by most researchers when performing RDE studies, may explain why the phenomenon of $\mathrm{FeN}_{\mathrm{x}}$ transformation into $\mathrm{Fe}$ oxides had not been observed previously. After load cycling in $\mathrm{O}_{2}$ at $25^{\circ} \mathrm{C}$, the $\mathrm{Fe}-\mathrm{N}-\mathrm{C}$ material looks exactly the same as the fresh material, except that it has significantly less $\mathrm{FeN}_{\mathrm{x}}$ moieties on the top surface. Bulk characterization techniques such as X-ray absorption spectroscopy and Mössbauer spectroscopy would show similar spectroscopic $\mathrm{FeN}_{\mathrm{x}}$ signatures before and after such an AST, and quantifying the amount of $\mathrm{FeN}_{\mathrm{x}}$ sites before/after requires significant amount of materials, which is typically not the case with RDE studies.

To demonstrate that the reported Fe oxide nanoparticle formation from some $\mathrm{FeN}_{\mathrm{x}}$ sites during $\mathrm{O}_{2}$-saturated load cycling at $80^{\circ} \mathrm{C}$ in $\mathrm{RDE}$ is also transposable to the PEMFC operating conditions, we applied the $\mathrm{O}_{2}$-LC AST between 0.6 and $1.0 \mathrm{~V}$ at $80^{\circ} \mathrm{C}$ in PEMFC on a $\mathrm{Fe}_{0.5} \mathrm{RP}$ cathode. TEM images of cathode fragments after $\mathrm{O}_{2}$ - $\mathrm{LC}$ reveal a high concentration of $\mathrm{Fe}$ nanoparticles (Figure S13a-b), while the activity at $0.8 \mathrm{~V}$ decreased from 22 to $4 \mathrm{~mA} \cdot \mathrm{cm}^{-2}$ during this AST (Figure S14). The observed nanoparticles are probably Fe oxides, based on the results from the RDE study. The nanoparticle size observed after $\mathrm{O}_{2}-\mathrm{LC}$ in PEMFC is ca. $10 \mathrm{~nm}$ for the largest ones, similar to the size observed after $\mathrm{O}_{2}$-LC in RDE (Figure $3 \mathbf{b}$-c), with many particles being even smaller. The formation and/or reprecipitation of $\mathrm{Fe}$ oxide particles seems however inhomogeneous in the cathode layer, as shown by the complete absence of particles in other locations, Figure S13c-d. This may be due to inhomogeneous through-plane utilization of the cathode during ORR at $0.6 \mathrm{~V}$ in the $\mathrm{O}_{2}$ - $\mathrm{LC}$ protocol, and/or to the migration of formed $\mathrm{Fe}$ oxide particles from the membrane-cathode interface to the cathodeGDL interface. The normalized ORR mass activity at $0.8 \mathrm{~V}$ after $\mathrm{O}_{2}-\mathrm{LC}$ (normalized to the initial activity measured in each setup) is comparable but slightly lower in PEMFC than in RDE, ca 0.18 and 0.35 , respectively. This enhanced deactivation in PEMFC might be due to the thicker cathode loading, $4 \mathrm{mg} \mathrm{cm}^{-2}$, vs. $0.8 \mathrm{mg}$ $\mathrm{cm}^{-2}$ used in RDE for Figure 2, and this correlates with the cathode loading effect reported in RDE in Figure S8. Alternatively, it could be due to the much higher ORR currents produced at 0.6 $V$ in PEMFC than in RDE. Our observations are also in line with a recent study from Zhang et al. ${ }^{[25]}$ on a similar Fe-N-C catalyst with exclusively atomically dispersed $\mathrm{FeN}_{\mathrm{x}}$ sites initially. Fe particles were observed after PEMFC operation at $0.85 \mathrm{~V}$ for $100 \mathrm{~h}$, while the normalized current density at $0.85 \mathrm{~V}$ decreased to 0.3 .

Our findings thus unravel an unexpected degradation mechanism, which we name as ROS-induced carbon corrosion, shedding fundamental light on the complexity of degradation mechanisms of $\mathrm{Fe}-\mathrm{N}-\mathrm{C}$ catalysts when performing ORR in application conditions. We also show that the nitrite stripping method cannot be easily applied to count the number of $\mathrm{FeN}_{\mathrm{x}}$ sites on aged $\mathrm{Fe}$ $\mathrm{N}-\mathrm{C}$ catalysts, unless $\mathrm{Fe}$ oxides can be avoided during or removed after the AST. Also, we stress that the nitrite stripping method is sensitive to $\mathrm{Fe}^{2+}$ and not $\mathrm{Fe}^{3+}$, thus the absolute amount of sites might be underestimated. Novel methods that can differentiate between $\mathrm{Fe}$ oxides and $\mathrm{FeN}_{\mathrm{x}}$ sites are therefore needed, in order to better follow the fate of $\mathrm{FeN}_{\mathrm{x}}$ sites during PEMFC operation. Last, our results show that a significant fraction of $\mathrm{FeN}_{\mathrm{x}}$ sites survived the aggressive load cycling in pure $\mathrm{O}_{2}$ at $80^{\circ} \mathrm{C}$, and it will be important in the near future to understand which are the poorly stable $\mathrm{FeN}_{\mathrm{x}}$ sites and which are the more stable ones within Fe-N-C class of materials, in order to rationally target the synthesis of novel Fe-N-C materials with increased site density of the stable $\mathrm{FeN}_{\mathrm{x}}$ sites.

\section{Conclusion}

In summary, by varying the temperature, the upper and lower limits of electrochemical potential during load cycling in RDE and the gas atmosphere, we have clarified the important role of oxygen in the degradation of $\mathrm{Fe}-\mathrm{N}-\mathrm{C}$ nanocatalysts used at PEMFC cathodes. Our results demonstrate that load cycling (0.3$0.7,0.5-0.9$ or $0.6-1.0 \mathrm{~V} v \mathrm{vs}$. $\mathrm{RHE}$ ) in the presence of $\mathrm{O}_{2}$ leads to unexpected carbon corrosion at such potentials and to the loss of a significant fraction of the atomically-dispersed $\mathrm{FeN}_{\mathrm{x}}$ sites. When load cycling is performed at $25^{\circ} \mathrm{C}$ in $\mathrm{RDE}$, the leached Fe cations exit the cathode layer while at $80^{\circ} \mathrm{C}$ they precipitate as Fe oxide particles. In parallel, the normalized ORR activity at $0.8 \mathrm{~V}$ vs. RHE 
decreased to $35 \%$, in line with the decrease in the site density of $\mathrm{FeN}_{\mathrm{x}}$ sites as probed by local X-EDS analyses. The unexpected carbon corrosion is relatively independent of the upper and lower limits during load cycling (provided ORR occurs), but dependent on cathode loading or thickness. This strongly suggests that $\mathrm{H}_{2} \mathrm{O}_{2}$ and/or reactive oxygen species produced as a by-product of ORR on Fe-N-C catalysts is responsible for this type of carbon corrosion. These findings shed fundamental light on the complex degradation mechanism of $\mathrm{Fe}-\mathrm{N}-\mathrm{C}$ cathode catalysts for PEMFC in operating conditions.

\section{Acknowledgements}

This work was performed within the framework of the Centre of Excellence of Multifunctional Architectured Materials "CEMAM" no ANR-10-LABX-44-01. The authors thank Synchrotron SOLEIL (Gif-sur Yvette, France) for provision of synchrotron radiation facilities at beamline SAMBA (proposal number 20171318) and Région Ile-de-France for convention SESAME E1845 for the support of the JEOL JEM-ARM200F electron microscope installed at Université de Paris. This study was financially supported by the French National Research Agency through the CAT2CAT project (grant number ANR-16-CE05-0007-03).

Keywords: Oxygen Reduction Reaction; Fe-N-C Catalysts; Polymer Electrolyte Membrane Fuel Cell; Degradation Mechanisms; Reactive Oxygen Species-Catalyzed Carbon Corrosion.

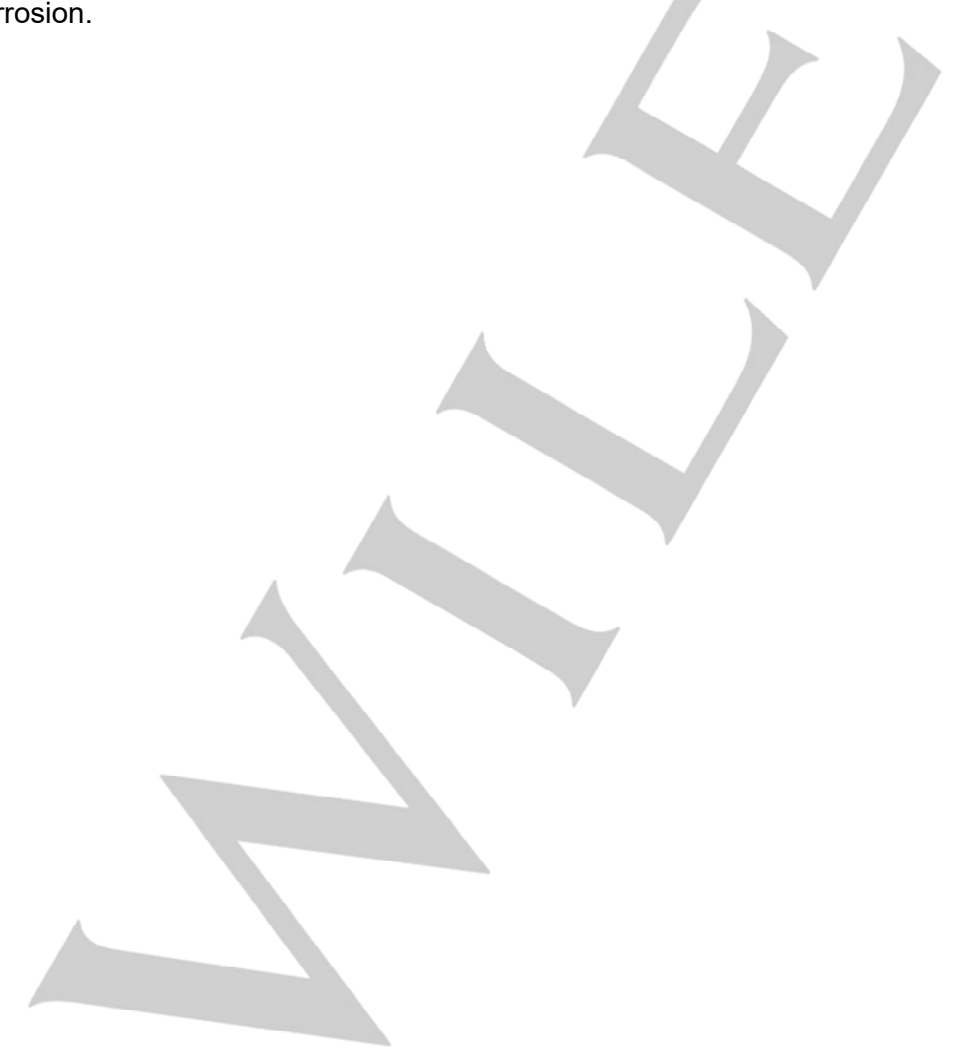


WILEY-VCH

\section{RESEARCH ARTICLE}

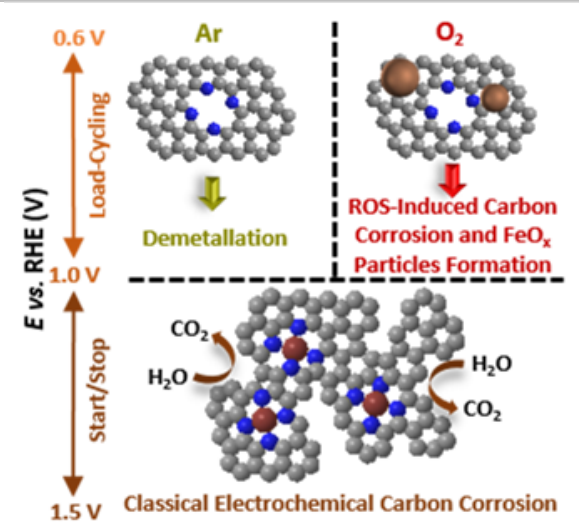

Stability of Fe-N-C electrocatalysts in polymer electrolyte membrane fuel cell environment is crucial but what governs it? In this contribution, we show that reactive oxygen species (ROS) being produced between $\mathrm{H}_{2} \mathrm{O}_{2}$ (a subproduct of the oxygen reduction reaction) and Fe sites via Fenton reactions transform atomicallydispersed $\mathrm{FeN}_{\mathrm{x}}$ sites into $\mathrm{Fe}$ oxides.
Kavita Kumar, Laetitia Dubau, Michel Mermoux, Jingkun Li, Andrea Zitolo, Jaysen Nelayah, Frédéric Jaouen, Frédéric Maillard*

Page No. - Page No.

On the Influence of Oxygen On the Degradation of Fe-N-C Catalysts

a) T. Asset, R. Chattot, M. Fontana, B. Mercier-Guyon, N. Job, L. Dubau, F. Maillard, Chemphyschem 2018, 19, 1552-1567; b) R. Chattot, O. Le Bacq, V. Beermann, S. Kühl, J. Herranz, S. Henning, L. Kühn, T. Asset, L. Guétaz, G. Renou, J. Drnec, P. Bordet, A. Pasturel, A. Eychmüller, T. J. Schmidt, P. Strasser, L. Dubau, F. Maillard, Nature Mater. 2018, 17, 827-833.

[2] D. Malko, A. Kucernak, T. Lopes, Nat. Commun. 2016, 7, 13285.

[3] R. Pavlicek, S. C. Barton, N. Leonard, H. Romero, S. McKinney, G. McCool, A. Serov, D. Abbott, P. Atanassov, S. Mukerjee, J. Electrochem. Soc. 2018, 165, F589-F596.

a) M. Lefèvre, J. P. Dodelet, Electrochim. Acta 2003, 48, 2749-2760; b) V. Goellner, V. Armel, A. Zitolo, E. Fonda, F. Jaouen, J. Electrochem. Soc. 2015, 162, H403-H414.

[5] C. H. Choi, H.-K. Lim, M. W. Chung, G. Chon, N. Ranjbar Sahraie, A. Altin, M.-T. Sougrati, L. Stievano, H. S. Oh, E. S. Park, F. Luo, P. Strasser, G. Dražić, K. J. J. Mayrhofer, H. Kim, F. Jaouen, Energy Environ. Sci. 2018, 11, 3176-3182.

[6] J. Herranz, F. Jaouen, M. Lefèvre, U. I. Kramm, E. Proietti, J. P. Dodelet, P. Bogdanoff, S. Fiechter, I. Abs-Wurmbach, P. Bertrand, T. M. Arruda, S. Mukerjee, J. Phys. Chem. C 2011, 115, 16087-16097.

[7] a) C. H. Choi, C. Baldizzone, G. Polymeros, E. Pizzutilo, O. Kasian, A. K. Schuppert, N. Ranjbar Sahraie, M. T. Sougrati, K. J. J. Mayrhofer, F. Jaouen, ACS Catal. 2016, 6, 3136-3146; b) C. H. Choi, W. S. Choi, O. Kasian, A. K. Mechler, M. T. Sougrati, S. Bruller, K. Strickland, Q. Jia, S. Mukerjee, K. J. J. Mayrhofer, F. Jaouen, Angew. Chem. 2017, 56, 8809-8812; c) K. Kumar, P. Gairola, M. Lions, N. Ranjbar-Sahraie, M. Mermoux, L. Dubau, A. Zitolo, F. Jaouen, F. Maillard, ACS Catal. 2018, 8, 11264-11276; d) R. Chenitz, U. I. Kramm, M. Lefèvre, V. Glibin, G. Zhang, S. Sun, J. P. Dodelet, Energy Environ. Sci. 2018, 11, 365-382.

[8] C. H. Choi, C. Baldizzone, J. P. Grote, A. K. Schuppert, F. Jaouen, K. J. Mayrhofer, Angew. Chem. 2015, 54, $12753-12757$.

[9] a) J. Durst, A. Lamibrac, F. Charlot, J. Dillet, L. F. Castanheira, G. Maranzana, L. Dubau, F. Maillard , M. Chatenet, O. Lottin, Appl. Catal. B 2013, 138-139, 416-426; b) L. Castanheira, W. O. Silva, F. H. B. Lima, A. Crisci, L. Dubau, F. Maillard, ACS Catal. 2015, 5, 2184-2194; c) I. Martinaiou, A. Shahraei, F. Grimm, H. Zhang, C. Wittich, S. Klemenz, S. J. Dolique, H. J. Kleebe, R. W. Stark, U. I. Kramm, Electrochim. Acta 2017, 243, 183-196; d) Y. Shao, J. P. Dodelet, G. Wu, P. Zelenay, Adv. Mater. 2019; e) D. Banham, S. Ye, K. Pei, J. I. Ozaki, T. Kishimoto, Y. Imashiro, J. Power Sources 2015, 285, 334-348.

(acta 2013, 110, 273-281; b) J. C. Meier, I. Katsounaros, C. Galeano, H. J. Bongard, A. A. Topalov, A. Kostka, A. Karschin, F. Schueth, K. J. J. Mayrhofer, Energy Environ. Sci. 2012, 5, 9319-9330; c) J. C. Meier, C. Galeano, I. Katsounaros, J. Witte, H. J. Bongard, A. A. Topalov, C. Baldizzone, S. Mezzavilla, F. Schüth, K. J. J. Mayrhofer, Beilstein J. Nanotechnol. 2014, 5, 4467.

[11] X. Yin, P. Zelenay, ECS Trans. 2018, 85, 1239-1250.

U. Martinez, S. Komini Babu, E. F. Holby, H. T. Chung, X. Yin, P. Zelenay, Adv. Mater 2019, 0, 1806545.

S. Baranton, C. Coutanceau, C. Roux, F. Hahn, J. M. Leger, J. Electroanal. Chem. 2005, 577, 223-234.

E. Proietti, F. Jaouen, M. Lefèvre, N. Larouche, J. Tian, J. Herranz, J. P. Dodelet, Nat. Commun. $2011,2$.

V. Armel, J. Hannauer, F. Jaouen, Catalysts 2015, 5, 1333-1351.

a) S. Wagner, H. Auerbach, C. E. Tait, I. Martinaiou, S. C. N. Kumar, C. Kübel, I. Sergeev, H.-C. Wille, J. Behrends, J. A. Wolny, V. Schünemann, U. I. Kramm, Angew. Chem. Int. Ed. 2019, 58, 10486-10492; b) T. Mineva, I. Matanovic, P. Atanassov, M.-T. Sougrati, L. Stievano, M. Clémancey, A. Kochem, J.-M. Latour, F. Jaouen, ACS Catal. 2019, 9359-9371.

[17] D. E. Beltrán, S. Litster, ACS Energy Lett. 2019, 4, 1158-1161.

[18] a) V. Goellner, C. Baldizzone, A. Schuppert, M. T. Sougrati, K. J. J. Mayrhofer, F. Jaouen, Phys. Chem. Chem. Phys. 2014, 16, 18454-18462; b) U. I. Kramm, A. Zana, T. Vosch, S. Fiechter, M. Arenz, D. Schmeißer, J. Solid State Electrochem. 2016, 20, 969-981.

[19] a) F. Jaouen, D. Jones, N. Coutard, V. Artero, P. Strasser, A. Kucernak, Johnson Matthey Technol. Rev. 2018, 62, 231-255; b) D. Myers, in Hydrogen and Fuel Cells Program 2018 Annual Merit Review and Peer Evaluation Meeting, 2018; c) P. Strasser, in $235^{\text {th }}$ ECS Meeting, Dallas, USA, 2019.

U. Tylus, Q. Jia, K. Strickland, N. Ramaswamy, A. Serov, P. Atanassov, S. Mukerjee, J. Phys. Chem. C 2014, 118, 8999-9008.

L. Dubau, F. Maillard Electrochem. Commun. 2016, 63, 65-69.

M. Pourbaix, Atlas of electrochemical equilibria in aqueous solutions, Vol. 1, Pergamon, 1966.

B. Beverskog, I. Puigdomenech, Corros. Sci. 1996, 38, 2121-2135.

A. Sadezky, H. Muckenhuber, H. Grothe, R. Niessner, U. Pöschl, Carbon 2005, 43, 1731-1742.

H. Zhang, H. T. Chung, D. A. Cullen, S. Wagner, U. I. Kramm, K. L. More, P. Zelenay, G. Wu, Energy Environ. Sci. 2019, 12, $2548-2558$. 